\title{
Health Canada's Progressive Licensing Framework
}

\author{
Neil Yeates, David K. Lee, Maurica Maher
}

$\infty$

See related article page 1848

$\mathrm{H}$ ealth Canada is modernizing the regulatory process for pharmaceutical and biologic products through a project called the Progressive Licensing Framework. ${ }^{1}$ Through this initiative, Health Canada is developing a new framework consisting of laws, regulations and guidelines that will support timely access to drugs and provide a mechanism for the continuous monitoring and reassessment of a drug's safety, quality and effectiveness throughout its life cycle. The 4 key elements of this framework are the adoption of a life-cycle approach (Fig. I), evidence-based decision-making, good planning and accountability. Combined, these 4 elements are the foundation of the new framework that will support health care professionals and patients in making decisions about drug therapy by ensuring that they have access to both the drugs and the necessary information to make the best use of them.

Under the current regulatory system, drug manufacturers are required to file a submission to Health Canada that contains information about the scientific, animal and clinical studies that have been performed (Fig. 2). The data are reviewed to assess the safety, efficacy and quality of the drug. If the information is found to comply with the Food and Drug Regulations, the manufacturer receives permission to market the drug. After the drug reaches the market, there are few obligations on manufacturer; however, adverse drug reactions must be reported to Health Canada. Under the current system, Health Canada cannot require a manufacturer to conduct postmarket activities such as performing studies of a drug's long-term safety or issuing warnings of potential drug risks.

Although this system has served Canadians well, Health Canada needs to modernize its approach to address current realities and emerging challenges. Rapid evolution in science and technology requires a modern regulatory system that can assess new types of drugs (e.g., biologics and genetic therapies) in a timely manner. There is a need for enhanced postmarket surveillance of drugs, especially in the wake of the recent high-profile withdrawal of drugs from the market. Patients are requesting that Health Canada become more transparent and that patients be allowed greater autonomy in making drug choices. Worldwide, drug regulatory agencies are recalibrating their premarket assessment systems to take into account the ongoing collection of knowledge gained throughout a drug's life cycle (Table I).

Implementation of the Progressive Licensing Framework will shift the focus from premarket assessment to continuous assessment. Health Canada will continue its role in approving drugs before they reach the market and will also assess the benefit-risk profile of drugs throughout their life cycle. There are increasing calls for Health Canada to be

more involved in the continued assessment of drugs after they reach the market.

Health Canada anticipates that progressive licensing will have many advantages. The new framework is intended to support accountable, evidence-based decision-making in drug management; thus, Health Canada expects there to be a better capacity in the regulatory system to plan for, manage and communicate risks as new information is obtained. This will result in improved access to current and accurate information for consumers, patients and health professionals. Progressive licensing will also mean increased flexibility in the regulatory system to address particular medical needs or exceptional circumstances, such as rare diseases or compassionate use, as well as a better alignment of Canada's regulatory standards with international standards, recognizing that the development and monitoring of drugs is now occurring on a global scale. Finally, accountability throughout the process, for both Health Canada and industry, will require that the justifications for decisions be transparent. Health Canada's fundamental mandate is to promote and protect the health and safety of all Canadians, and Health Canada is pursuing the progressive licensing approach because it is believed to provide the tools required to fulfill this mandate.

The Progressive Licensing Framework, still in early development, began with an intensive research phase, compiling the best international regulatory practices and learning how other regulators have modernized their systems. Health Can-

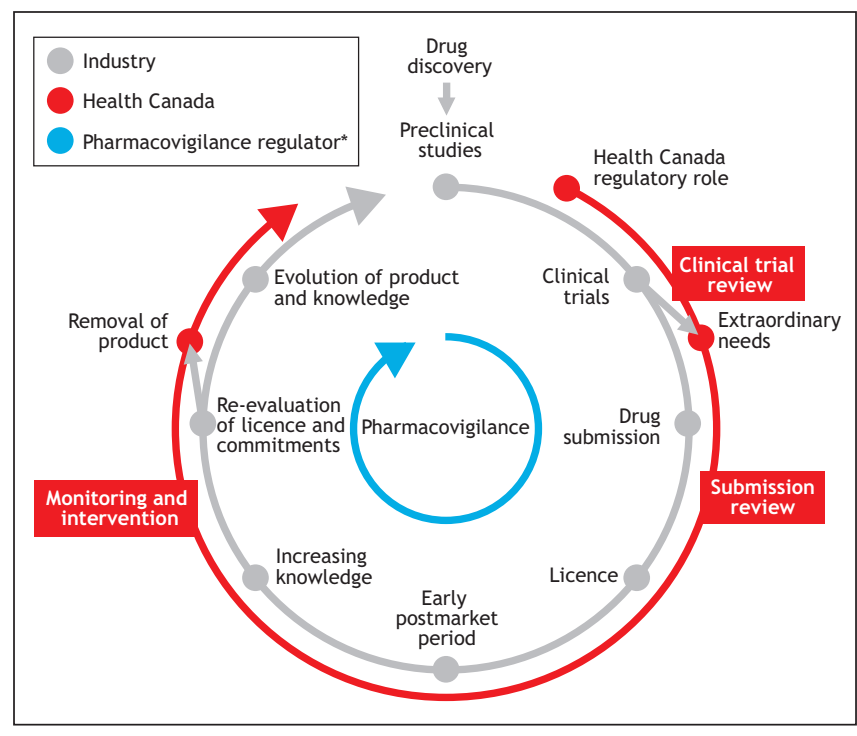

Fig. 1: The "life cycle" of a drug. *Includes input from industry, health professionals and the public. 
ada has also systematically assessed the strengths and weaknesses of and gaps in the current regulatory framework. In spring 2006, Health Canada opened the process and sought the early inclusion of decision-makers such as the provinces and territories, health care professionals, industry and patients by inviting them to participate in ongoing discussions and workshops.

A number of common themes have emerged from the research and consultations to date. There is agreement that the new framework should be focused on patients and that drug safety should remain a paramount concern at the federal level. There is also agreement that a drug's benefits and risks should be assessed throughout its life cycle. Furthermore, any changes to the system should eliminate duplication and inefficiency in data collection and in communication of information about drug benefits and risks.
Areas that will merit extensive exploration include the evidence required to initially license a drug for market, especially for those that meet a previously unmet medical need and are therefore desired quickly by patients, or for drugs that present challenges in the collection of initial data, such as a drug for a very small target population.

In developing the Progressive Licensing Framework, Health Canada will continue to include decision-makers such as the provinces and territories, industry, health care professionals and patients to ensure that the resulting system is one that will benefit all Canadians. Discussions are expected to narrow into a practical assessment of the proposed regulatory structure and will include legal authorities. This assessment will include an analysis of how these potential changes will affect the health care system. Feedback was sought through workshops held in May and June of 2007; other meetings will continue through

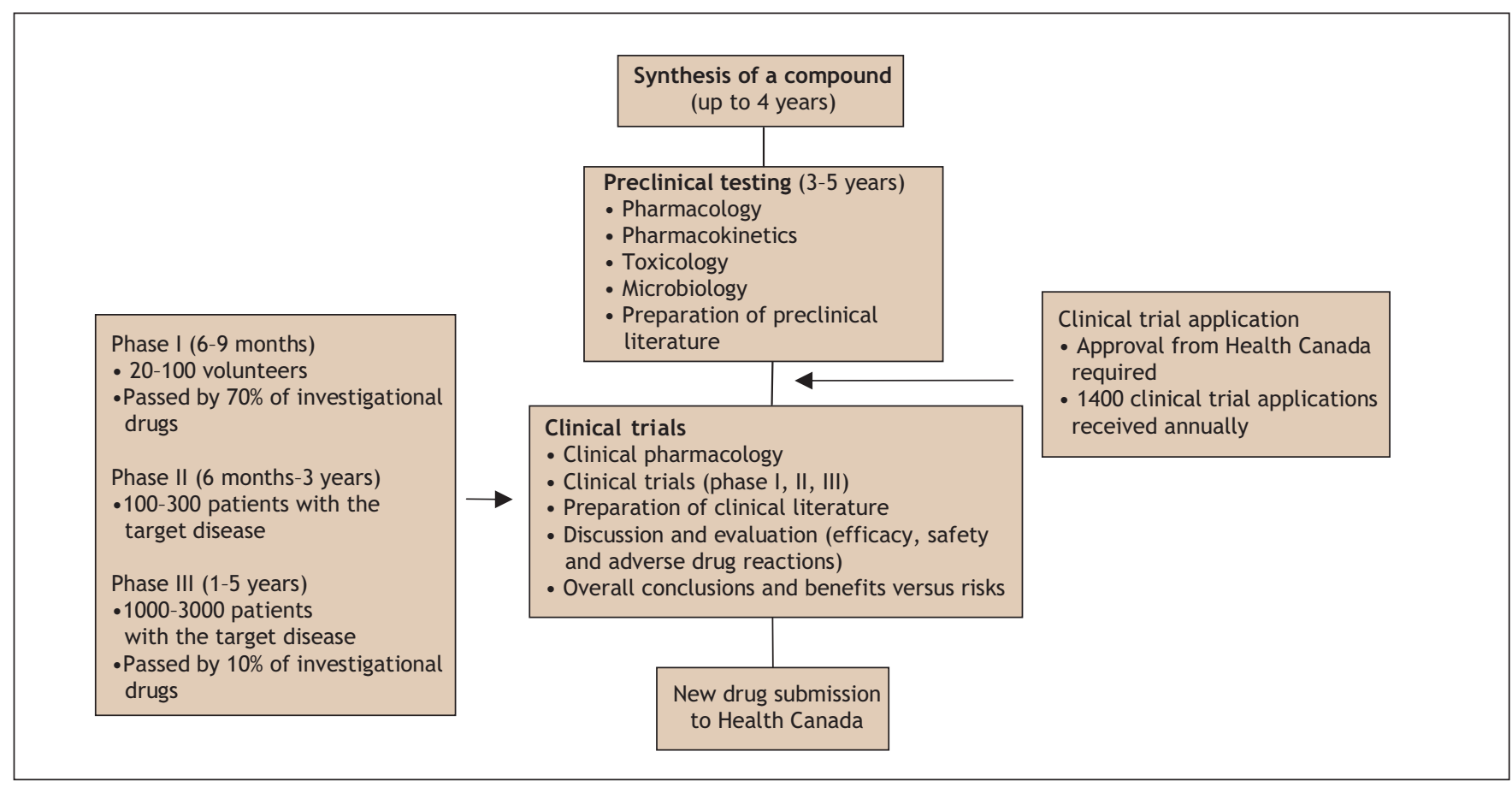

Fig. 2: The current drug development and regulatory process in Canada.

Table 1: Features of pre- and postmarket drug assessment in the United States and the European Union

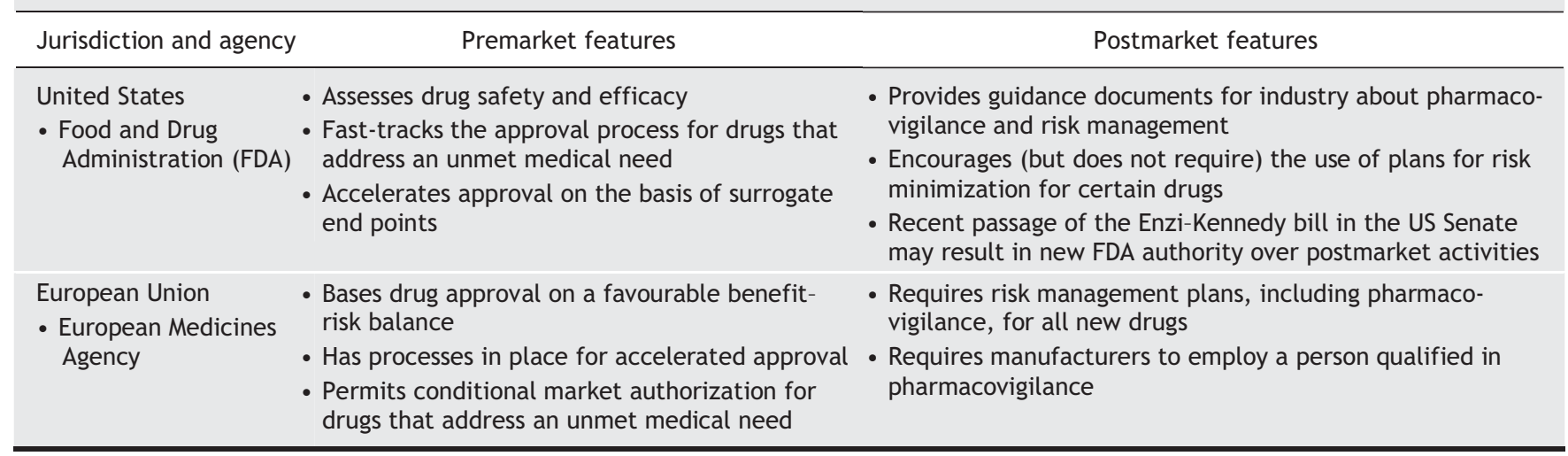


fall 2007. Comments can also be submitted through the Progressive Licensing Web site until the end of August 2007. A formal consultation phase will be initiated after prepublication of the regulations, anticipated to occur in 2008.

The experience and views of physicians and other health care professionals are critical in helping create a framework that will support them in formulating benefit-risk assessments and in providing their patients with the best care possible. To ensure that the new system of drug regulation is patient-centred and supports the optimal use of drugs by maximizing the benefits and minimizing the risks, Health Canada welcomes your feedback. For more information about the Progressive Licensing Framework, please visit www .healthcanada.gc.ca/progressive_licensing.

Neil Yeates, David Lee and Maurica Maher are with Health Canada. Neil Yeates is Assistant Deputy Minister for the Health Products and Food Branch, Health Canada, Ottawa, Ont.
Competing interests: None declared.

Contributors: All of the authors contributed to the conception and design, the writing and revision of the article, and gave final approval of the version submitted for publication.

Acknowledgements: We thank Supriya Sharma for reviewing the manuscript, coordinating its submission and providing supervision to the team. We also thank Marilyn Schwartz and Nick McCandie Glustien for the illustrations.

\section{REFERENCE}

I. Health Canada. The Progressive Licensing Framework Concept Paper for Discussion. Available: www.hc-sc.gc.ca/dhp-mps/prodpharma/activit/consultation /proglic_homprog_concept_e.html (accessed 2007 May 24).

Correspondence to: Mr. Neil Yeates, Health Products and Food Branch, Health Canada, 250 Lanark Ave., Ottawa ON KIA oKg; fax 6r3 957-3954; neil_yeates@hc-sc.gc.ca

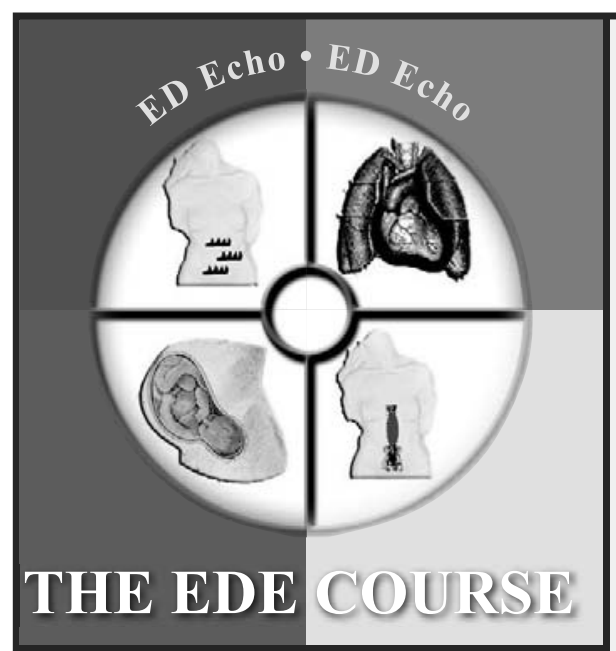

NOW AVAILABLE ON DVD Includes

$\downarrow D V D$ with all lectures from The EDE Course including "Introduction \& Physics" and "Conclusion" - running time 205 minutes

$\downarrow$ Bonus Lecture on Vascular Access

$\downarrow$ Data CD with Course Texts for EDE Course and Vascular Access module and testing material for CME credits

\section{Learn to Use the Stethoscope of the 21st Century}

\section{Featuring Lectures On}

Cardiac EDE

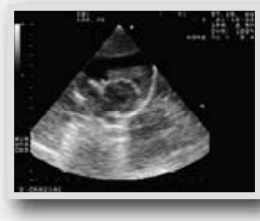

DETECT

pericardial effusions
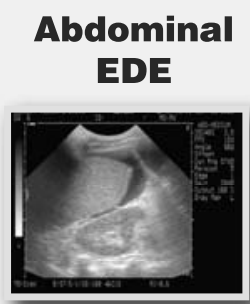

DETECT

intra-abdominal hemorrhage and cardiac standstill
Aortic EDE

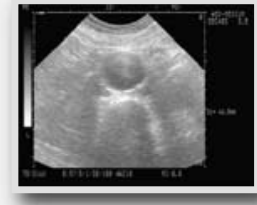

DETECT

abdominal aortic aneurysm

Obstetrical EDE

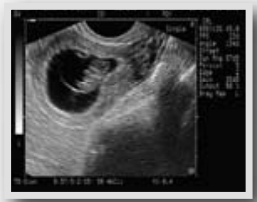

DETECT intrauterine pregnancy
Beginning in 2001, The EDE - ED Echo Course has been taught more than 250 times to over 3000 Canadian physicians. Over 100 EDE Instructors now teach this material in all ten provinces and two territories, making EDE

"Canada's National Emergency Ultrasound Course"

The EDE Course is unique in that it has continually evolved as the instructors gained insight into the way that physicians learn this skill. As they did so, they developed numerous techniques to help students acquire a basic understanding of ultrasound image generation and interpretation. All this experience has been distilled into the Spring 2007 version of the course lectures and the 5th edition of the course text. Learners may now participate in (or review) the didactic portion of the course on their own time. The material is presented in the trademark EDE style: simplicity, humor and a minimum of esoterica.

For more information about The EDE Course, or to arrange for the course to come to your center, please write the Course Director at portray@vianet.ca

To obtain this DVD please send cheque or money order for \$295 to "The EDE Course" 55 Windsor Crescent, Sudbury, Ontario P3E $1 Z 6$ 